\title{
Prevalence of Oral Maxillary and Mandibular Tori among Outpatients Attending Dental Collage in Basra Governorate Southern of Iraq
}

\author{
Nadia Azzam Al-Shareeda ${ }^{1}$, Majed Mohamed Refaat ${ }^{2}$, Abdullah M. Hussain ${ }^{3}$ \\ ${ }^{1}$ Assistant Lecturer, Pedodontics, Orthodontics and Preventive Dentistry, College of Dentistry, University of \\ Basrah, Basrah, Iraq, ${ }^{2}$ Assistant Lecturer, Prosthetic Dentistry, ${ }^{3}$ Assistant Lecturer, Restorative and Aesthetic \\ Dentistry, College of Dentistry, University of Basrah, Basrah, Iraq
}

\begin{abstract}
The objectives of the study is the assessment of torus palatinus (TP) prevalence as well as torus mandibular is (TM) among different gender and age groups. Seven hundred and fifty (750) out door patients (380 male and 370 female) were tested for the tori presence or absence at dentistry collage in Basrah city between January 2019 and June 2019. Sex, gender and location factors were evaluated. The prevalence rate of TP was $4.73 \%$ for male and $5.13 \%$ for female, and the prevalence rate of TM was $2.36 \%$ for male and $3.24 \%$ for female. In females, TP prevalence was more compared to males. The TP incidence more commonly in middle aged persons, While the TM more commonly in older persons.
\end{abstract}

Keywords: Exostosis, Prevalence, Tori.

\section{Introduction}

Tori arenon-pathologic bony exostosis that are consist of dense cortical bone covered by thin mucosa with poor vascularization ${ }^{1}$. Thin mucosal membrane covering the tori easily traumatized by removable dental prosthesis unless adequate relief is provided. Surgical removal is mandatory if large exostosis cause trauma or interference with artificial removable replacement insertion or with its function ${ }^{2}$. TP mostly found along the mid suture of the hard palate, and TM located in areas of premolar and canine at the mandible lingual aspect, usually bilateral ${ }^{3}$. TP has four shapes flat, nodular, lobular and spindle $e^{4.5}$. The etiology of both tori has been subjected multifactorial due to genetic, mastication, environmental and continued growth ${ }^{6,7}$. TP has been found more common in females, while TM more frequently in males. Tori usually are noticed in young and middle age adulds ${ }^{8}$.

Objectives: The study aimed to investigate the location and prevalence of TP and TM. Also determine the correlation between current findings and population gender and age.

\section{Materials and Method}

Patients of seven hundred and fifty (380 male and 370 female) randomly selected outdoor admitted at Dentistry College/Basrah University between January to June 2019. Detailed questioner sheet prepared for the study, subjects were stratified depend on their age into 5age categories: (20-29, 30-39, 40-49, 50-59, $\geq 60$ years).To prevent inter examiner bias, one author clinically examine all the subjects for tori absenceor presence through clinical palpation and inspection, the subject who has questionable tori was excluded. Raised bony exostosis located in the hard palatal midline defined as torus palatinus, raised bony exostosis situated in mandibular lingual aspect defined as being torus mandibularis.

The collected data were inserted in a computerized spreadsheet (Microsoft Excel 2013) and analyzed by SPSS version 20.

\section{Results}

Among the 750 male and female studied subjects, 58 person found having tori with a prevalence rate of $7.73 \%$ as shown in table 1 . TP was presented in 37 
subjects with a prevalence rate of $4.93 \%$ the males were $18(4.73 \%)$ and the females were $19(5.13 \%)$, whereas TM was detected in 21 subjects expressing $2.8 \%$ prevalence rate,males were $9(2.36 \%)$ and the females were $12(3.24 \%)$. Table 2 summarize this distribution according to sex.

Table 1:Tori Prevalence in different groups

\begin{tabular}{|c|c|c|c|}
\hline Age Groups & M+F (Total) & $\begin{array}{c}\text { M+F with } \\
\text { tori }\end{array}$ & $\begin{array}{c}\% \\
\text { Prevalence }\end{array}$ \\
\hline $20-29$ & 175 & 9 & 5.14 \\
\hline $30-39$ & 170 & 15 & 8.82 \\
\hline $40-49$ & 175 & 19 & 10.85 \\
\hline $50-59$ & 150 & 10 & 6.66 \\
\hline$\geq 60$ & 80 & 5 & 6.25 \\
\hline Total & $\mathbf{7 5 0}$ & $\mathbf{5 8}$ & $\mathbf{7 . 7 3}$ \\
\hline
\end{tabular}

Table 2: Tori distribution in male and female

\begin{tabular}{|l|c|c|c|}
\hline Tori & Male (\%) & Female (\%) & Total (\%) \\
\hline Torus palatinus & $18(4.73)$ & $19(5.13)$ & $37(4.93)$ \\
\hline Torus mandibularis & $9(2.36)$ & $12(3.24)$ & $21(2.8)$ \\
\hline Total & $\mathbf{2 7 ( 7 . 1 )}$ & $\mathbf{3 1 ( 8 . 3 7 )}$ & $\mathbf{5 8 ( 7 . 7 3 )}$ \\
\hline
\end{tabular}

Most patients located at 40-59 years age group and tori incidence decreased over the 60 years old. The prevalence in each age groups seen in table 3.

Table 3: Prevalence of TP and TM based on gender and age

\begin{tabular}{|c|c|c|c|c|c|c|}
\hline \multirow{2}{*}{$\begin{array}{c}\text { Age groups } \\
(\text { years) }\end{array}$} & Torus palatinus & Torus palatinus & Torus palatinus & $\begin{array}{c}\text { Torus } \\
\text { mandibularis }\end{array}$ & $\begin{array}{c}\text { Torus } \\
\text { mandibularis }\end{array}$ & $\begin{array}{c}\text { Torus } \\
\text { mandibularis }\end{array}$ \\
\cline { 2 - 7 } & Male (\%) & Female (\%) & Total (\%) & Male (\%) & Female (\%) & Total (\%) \\
\hline $20-29$ & $3(16.66)$ & $3(15.78)$ & $6(16.21)$ & $1(11.11)$ & $2(16.66)$ & $3(13.28)$ \\
\hline $30-39$ & $4(22.22)$ & $7(36.84)$ & $11(29.72)$ & $2(22.22)$ & $2(16.66)$ & $4(19.4)$ \\
\hline $40-49$ & $8(44.44)$ & $6(31.57)$ & $14(37.83)$ & $2(22.22)$ & $3(25)$ & $5(23.80)$ \\
\hline $50-59$ & $2(11.11)$ & $3(15.78)$ & $5(13.51)$ & $1(11.11)$ & $4(33.33)$ & $5(23.80)$ \\
\hline$\geq 60$ & $1(5.55)$ & $0(0)$ & $1(2.70)$ & $3(33.33)$ & $1(8.33)$ & $4(19.4)$ \\
\hline Total & $\mathbf{1 8 ( 1 0 0 )}$ & $\mathbf{1 9 ( 1 0 0 )}$ & $\mathbf{3 7 ( 1 0 0 )}$ & $\mathbf{9 ( 1 0 0 )}$ & $\mathbf{1 2}(\mathbf{1 0 0 )}$ & $\mathbf{2 1}(\mathbf{1 0 0})$ \\
\hline
\end{tabular}

\section{Discussion}

Tori of maxilla and mandible were detected as bony outgrowths slowly is growing at palatal midline and mandibular lingual aspect ${ }^{9,10}$. A Jordanian study had been reported that no significant difference in the prevalence between male and female among Jordanian population $29.8 \%{ }^{11}$. The racial divergence or ethnic groups may cause the tori prevalence varies among studies ${ }^{12,13}$. An Indian study showed torus prevalence being $9.5 \%$ in the palate and commonly occurred more in women in comparison to men ${ }^{14}$. Actually, no clear interpretation for such variance between sexes was identified, where genetics mightpropose being a fundamental contributing factor.

A significant finding of our study among this population was that TP $(4.93 \%)$ was more frequently seen than $\mathrm{TM}(2.8 \%)$.
Tori occurrence peak at third decade of life as mentioned by other observations ${ }^{15,16}$, our investigation illustrate the occurrence peak for both tori at fifth decade of life. With age, tori prevalence starts to increase until reaching the peak at 40-49 years old. After that the occurrence of both tori trend to decrease over the 50 year old, this is agreed with the findings of many authors ${ }^{16,17,18}$. Functional factors affect this variation, after teeth extraction the torus palatinusregression noticed. Eggen and Natvig ${ }^{19}$ showed same findings in Norwegians and summarized that prevalence decreased over the fifty years was attributed to remaining teeth numbers decrease, and also they associated the high TM prevalence with increasing the stress of mastication. Both tori was more common in female $(8.37 \%)$ as compared to male $(7.1 \%)$. 


\section{Conclusion}

a. More occurrence of tori in female compared to male.

b. Both tori prevalence is low at such region, and prevalence of TP is higher than the prevalence of TM.

c. The incidence to tori increased with age up to 50 years old.

Source of Funding: This study is self-funded

Disclosure/Conflict of Interest: The authors declare no conflict of interest.

Ethical Clearance: Ethical clearance from the institutional ethical committee obtained for the study.

\section{References}

1. Castro Reino O, Perez Galera J, Perez Cosio Martin J, Urbon Caballero J. Surgical techniques for the exeresis of torus, both palatal and mandibular. We observe indications, contra indications and complications as well as enumerate all the right events to realize correctly the said techniques. [Surgery of palatal and mandibular torus]. Rev Actual Odontoestomatol Esp. 1990; 50:47-50, 536.

2. Woo JK. Torus palatinus. Am J Phys Anthropol 1950;8:81- 111 .

3. Neville BW, Damm DD, Allen CM, Bouquot JE. In: Oral and Maxillofacial Pathology, 2nd edn. Philadelphia: WB Saunders 2002:20-1.

4. Eggen S, Natvig B, Gasemyr J. Variation in torus palatinus prevalence in Norway. Scand J Dent Res 1994;102:54-59.

5. Reichart PA, Neuhaus F, Sookasem M. Prevalence of torus palatinus and torus mandibularis in Germans and Thai. Community Dent Oral Epidemiol 1988;16:61-64.

6. Suzuki M, Sakai T. A familial study of torus palatinus and torus mandibularis. Am J Phys Anthropol 1960;18:263-72.

7. Topazian DS, Mullen FR. Continued growth of a torus palatinus. J Oral Surg 1977;35:845-6.
Medico-legal Update, January-March 2021, Vol. 21, No. 1

637

8. Reichart PA, Neuhaus F, Sookasem M. Prevalence of toruspalatinus and torus mandibularis in Germans and Thais Commun Dent Ora EpidemioI 1988;16:61-4.

9. Stephen T.S.; Robert C.F.; Leslie F Principle and Practice of Oral Medicine; W.B. Saunders Company: Philadelphia, 1984; pp 476-477.

10. Carl O.B. Current Clinical Dental Terminology; The C.V. Mosby Company: Saint Louis, 1974; pp 411-412.

11. Al Quran FA, Al-Dwairi ZN. Toruspalatinus and torus mandibularis in edentulous patients. $\mathrm{J}$ Contemp Dent Pract. 2006 May 1; 7(2):112-9.

12. Gorsky M, Bukai A, Shohat M. Genetic influence on the prevalence of torus palatinus. Am J Med Genet 1998;75: 138-40.

13. Bouqout IE, Gundlach KKH. Oral exophytic lesions in 23,616 white Americans over 35 years of age. Oral Surg Oral Med Oral Pathol1986;62:284-91.

14. Shah DS, Sanghavi SJ, Chawada JD, Shah RM. Prevalence of torus palatinus and torus mandibularis in 1000 patients. Indian J Dent Res 1992;3:107-10

15. Kolas, S.; Halperin, V.; Jefferis, K.; Huddleston, S.; Robinson, H. B. The Occurrence of Torus Palatinus and Torus Mandibularis in 2,478 Dental Patients. Oral Surg. Oral Med. Oral Pathol. 1953; 6: 11341141.

16. Wandee A; Aree J; Somporn S Torus Palatinusand Torus Mandibularis in a Thai Population. Science Asia 2002; 28: 105-111.

17. Bruce,I.;Ndanu, T. A.; Addo, M.E.Epidemiological Aspects of Oral Tori in a Ghanaian Community. Int. Dent. J. 2004; 54: 78-82.

18. Dosumu O.O.; Arotiba J.T.; Ogunyinka A.O. The Prevalence of Palatine and Mandibular Tori in a Nigerian Population. Odonto- Stomatologie Tropicale 1998; 6-8.

19. Eggen, S.; Natvig, B. Variation in Torus Mandibularis Prevalence in Norway. A Statistical Analysis Using Logistic Regression. Community Dent. Oral Epidemiol. 1991; 19: 32-35. 